\title{
ASPECTOS DE LA ACTIVIDAD DE DOÑA MARÍA JESÚS, EN LA UNIVERSIDAD DE ALICANTE
}

Míkel de EPALZA Universidad de Alicante

\section{Justificación del volumen de homenaje.}

Este volumen de Homenaje universitario a Doña María Jesús Rubiera Mata, Catedrática de Estudios Árabes e Islámicos en la Universidad de Alicante, es fruto de una iniciativa de sus compañeros de la Sección Departamental de Estudios Árabes e Islámicos de esta Universidad, al que se han adherido otros investigadores y amigos, de la Universidad de Alicante y de otras instituciones cientificas. En este capítulo del volumen, me compete, como coordinador de la iniciativa y colega más próximo a la homenajeada, explicar algunas de las razones que nos han llevado a rendirle este Homenaje, desde la Universidad de Alicante, donde la profesora Rubiera ejerce su labor docente e investigadora desde 1982.

Esta explicación es particularmente necesaria por el hecho, aparentemente singular, de que se le dedica a Doña María Jesús un volumen de Homenaje a una edad temprana, para lo habitual en nuestra vida universitaria. Estos honores académicos se suelen ofrecer -como ya se ha hecho en nuestra Universidad de Alicante- con ocasión de jubilaciones por edad (al catedrático de Filologia Inglesa Dr. Marcos';

${ }^{1}$ Estudios de Filología Inglesa: Homenaje al Doctor Pedro Jesús Marcos Pérez, Alicante, 1990. Participé con "Relaciones del cónsul británico Morgan con descendientes de moriscos en el Mágreb (siglo XVIII)", pp. 615-620. 
al profesor de Historia Medieval Dr. del Estal ${ }^{2}$ ) o por fallecimiento (al profesor titular de Estudios Árabes e Islámicos Dr. Villegas ${ }^{3}$ ). Pero también se da el caso de dedicar un volumen de homenaje a personajes en plenitud de actividad cientffica, docente e investigadora, a los cincuenta años, como es el caso de dos cientificos mallorquines amigos ${ }^{4}$.

El caso de Doña María Jesús Rubiera Mata es evidentemente un caso de reconocimiento excepcional, en la plenitud de sus facultades universitarias, docentes e investigadoras. Pero también es en cierta manera excepcional el conjunto de circunstancias que han justificado nuestra iniciativa, como se dirá brevemente en las páginas siguientes.

Además de sus méritos personales, hay ante todo un deseo de dar a conocer el aprecio que sus compañeros le tenemos, a tantos niveles personales y cientificos, y como alma y motor de este pequeño grupo de arabistas de la Universidad de Alicante. Hay también el deseo de celebrar, en esta Universidad de Alicante, algunos logros académicos de este grupo en este año 1994, logros en los que Rubiera ha tenido y tiene iniciativas cruciales: el haber salido la primera promoción del nuevo Tercer Ciclo y Doctorado en Filología Árabe; el haberse iniciado la nueva Licenciatura en Filología Árabe (antes, sólo había Primer Ciclo, dentro de la Licenciatura de Filologia Hispánica); el haber logrado alcanzar los diez años de la revista de investigación arabística Sharq Al-Ándalus. Estudios Árabes, con sus respectivos volúmenes anuales; el haberse culminado las enseñanzas biamuales de las dos promociones del Máster de "Estudios Euro-Árabes" que ella fundara en

${ }^{2}$ Homenaje al profesor Juan Manuel del Estal, Alicante, en prensa. Participo con "Nota sobre Benimagrell, antropónimo árabe-latino del siglo XIII y topónimo actual de Alicante".

${ }^{3}$ Mundo Arabe/Mundo Hispánico: Creatividad e Historia. Homenaje a Marcelino Villegas, Madrid, 1993. Participé con "Ortega y Gasset: tensión e integración de lo árabe y lo europeo", pp. 43-52.

${ }^{4}$ Estudis de Prehistòria, d'Història de Mayūrqa i d'Història de Mallorca dedicats a Guillem Rosselló i Bordoy, Mallorca, 1982, y Homenaje a Juan Nadal, Atenas, 1992. Participé con "Orígenes de la invasión cordobesa de Mallorca en 902", pp. 111-129, y "Mallorca bajo la autoridad compartida de Bizantinos y Árabes (siglos VIII-IX)", pp. 167-175, respectivamente. 
la Universidad de'Alicante y que desde aquí se han impartido en el CIDOB de Barcelona y la Universitat de Girona. Este volumen quiere ser también, por tanto, para nuestro grupo de la Universidad de Alicante, una forma modesta de reconocimiento de nuestra labor colectiva, bajo su dirección.

\section{Labor previa, en la Universidad Complutense de Madrid}

La labor universitaria de la Dra. Rubiera Mata ya era importante cuando se traslada a la Universidad de Alicante, por concurso-oposición, en 1982, desde la Universidad Complutense de Madrid, donde era Profesora Titular desde 1975.

Esa Universidad es la más antigua de España donde se enseñan sin discontinuidad los estudios árabes e islámicos, desde mediados del siglo XIX. Doña María Jesús se había licenciado en Filología Semítica (1965), había sido Profesora Ayudante (1966), se había doctorado (1972) con una tesis que dio origen a su libro Ibn al-Payyăb, el otro poeta de la Alhambra', y habra ganado por oposición la plaza de Profesora Adjunta (luego denominada Profesora Titular de Universidad) (1975).

A su labor de profesora e investigadora en aquel Departamento y a su participación internacional en congresos y otros encuentros científicos unfa su actividad militante para mejorar la enseñanza y vida universitarias, en diversos colectivos dinámicos de profesores. Ese interés bastante altruista y ese dinamismo inteligente para mejorar la sociedad eran características de esa época de transición política, en Europa y en España. María Jesús Rubiera Mata, universitaria e intelectual ya brillante, particiṕ activamente en esos movimientos y adquirió una experiencia que trajo con ilusión a la Universidad de Alicante.

Su traslado a la Facultad de Filosofía y Letras de Alicante se debió exclusivamente a causas familiares, por su matrimonio con el Profesor

${ }^{5}$ Primera edición, Granada, 1982, y segunda edición, Granada, 1994, con prólogo del arabista y académico de la Lengua Dr. Emilio García Gómez, también académico y Director de la Real Academia de la Historia. 
Titular de esa Universidad (hoy, también Catedrático de Estudios Árabes e Islámicos) Míkel de Epalza Ferrer.

María Jesús Rubiera Mata tenía sólo vinculaciones familiares muy remotas con la región alicantina: un antepasado suyo del siglo XIX, Pedro Mata y Fontanet, escritor y político, había sido el primer catedrático de Medicina Legal en la Universidad de Madrid y habra sido maestro del Dr. Esquerdo, que le animó a que se presentara a diputado por la circunscripción de Villajoyosa (ahora, la Vila Joiosa), a la que representó en las Cortes españolas. Conocía la región alicantina por estancias veraniegas frecuentes, desde su infancia, en Xàbia/Jávea y en Playa de San Juan. Con su nuevo destino profesional, Doña María Jesús emprende una nueva vida universitaria en Alicante. Sin dejar su actividad a nivel nacional e internacional, se interesa por conocer cientificamente la realidad regional, investiga numerosos aspectos de su historia -especialmente lo relacionado con su pasado árabe-islámico-, aprende y fomenta el catalán, también en su variante regional valenciana, y promueve animosamente actividades universitarias, especialmente en el área de los Estudios Árabes e Islámicos y en el marco de la Facultad de Filosoffa y Letras, en relación con las áreas más afines de Filología Catalana, Filología Clásica, Filología Española, Filología Francesa y hasta con el area de Filologia Inglesa, pero sin limitar a estos campos su estudio y su actividad.

A continuación, y como complemento a lo que otros colegas han escrito en este mismo volumen, se presentarán algunos de los campos más relevantes de su actividad universitaria, relevancia específica, que no debería hacer olvidar el buen hacer diario de nuestro mester de docentes e investigadores y sus ocupaciones paralelas administrativas universitarias, que también ha tenido que hacer.

\section{El Máster de "Estudios Euro-Árabes"}

Para promover los estudios árabes en la Universidad de Alicante, con nuevas formulas docentes universitarias al servicio de la sociedad de su ámbito regional, la Dra. Rubiera Mata idea y organiza unos estudios de Máster, de los primeros que se inician en esta Universidad. Es el "Máster de Estudios Euroárabes". 
Dada la escasez de posibilidades para financiarlo, ese Máster cuenta para su profesorado con Doctores benévolos de la propia Universidad de Alicante, en los ámbitos de los estudios árabes, del derecho y de la economía (Dres. Bermúdez, Epalza, Villegas, Ybarra y la propia Dra. Rubiera), con algunos profesores invitados. El título se da tras dos años de docencia.

El alumnado fue más escaso de lo previsto, en sus dos tercios miembros de la propia comunidad universitaria (hubo también alumnos de Murcia, y militares destinados en la región). Tras la formación de dos promociones (entre 1987 y 1990), se dejó en suspenso estos estudios, para reanudarlos eventualmente, más adelante.

Pero la fórmula ideada por Doña María Jesús correspondía también a una demanda catalana, que se concretarfa años después en un Máster de "Estudis Euro-Àrabs", que impartió la Universitat "Estudi General" de Girona, con la Fundación CIDOB de Barcelona, también con una duración de dos cursos y programando la formación de dos promociones. Este Máster se dio en los cursos 1991 a 1994, bajo la dirección académica de otro profesor de la Universidad de Alicante y con profesorado de esta Universidad y de otras, españolas, francesas y belgas.

Esta fórmula universitaria para formar a post-graduados expertos en el Mundo Árabe ha sido pionera en España, abriendo nuevas perspectivas, necesarias, a los estudios árabes e islámicos, además de las fórmulas tradicionales de la Licenciatura y Doctorado en Filologia Árabe (área de conocimiento "Estudios Árabes e Islámicos") y de los cursos más flexibles de las Universidades de Verano ${ }^{6}$.

Entre los muchos cursos y actividades docentes universitarias que alentó, cabe recordar un curso del I.C.E. "Semiótica del Arte y de la Arquitectura Árabes", sobre uno de sus temas de especialidad cientifica más exitoso, que organizó en el curso 1983-1984.

6 Ver presentación de esos cursos en M. de Epalza, "Formación e investigación universitarias sobre el Islam. Máster de Estudios Euro-Árabes (Alicante - Barcelona - Girona)" ${ }^{n}$, Simposio Internacional "Comunidades islámicas en España y en la Comunidad Europea" (El Escorial, 2-5 marzo 1993), en M. Abumalham (ed.), Comunidades islámicas en Europa, Madrid, 1995, pp. 213227. 


\section{La revista científica SHARQ AL-ÁNDALUS. ESTUDIOS ÅRABES}

A María Jesús Rubiera Mata se debe también la fundación y publicación de la revista cientifica Sharq Al-Ándalus. Estudios Árabes, que en 1994 cuenta ya con 10 volúmenes, además de dos apéndices bibliográficos y de la colección aneja, que también ella fundó y dirige ${ }^{7}$.

La historia de esta revista, como en todas las aventuras editoriales que supone fundar y llevar adelante una revista cientifica, tiene una prehistoria, que explica aspectos ilustrativos de la acción universitaria de la profesora Rubiera Mata.

En 1981, cuando aún Rubiera no estaba en la Universidad de Alicante, el nuevo Rector Antonio Gil Olcina, consciente de la importancia de las publicaciones científicas para promover la imagen de la joven Universidad, había lanzado una campaña para fomentar la fundación de revistas académicas, en las diversas áreas de investigación del Campus. En efecto, las publicaciones cientificas son la señal específica de la Universidad como centro de investigación superior, especialmente las revistas, por la regularidad y pluralidad de equipo que suponen. Los tres profesores de Historia Medieval y de Estudios Árabes e Islámicos (Dres. Blasco, del Estal y Epalza), reunidos desde hacía un año hasta en un mismo despacho, habíamos pensado en hacer una revista original en el panorama español : unir los "estudios árabes e hispanos medievales". El proyecto se vino abajo, por falta de apoyo económico de la Universidad y por disensiones con nuevos profesores medievalistas, mejores conocedores quizás de las tradicionales díficultades metodológicas de entendimiento entre arabistas y medievalistas, insuperables a veces, a pesar de la ingenua buena voluntad de los que habían tenido la idea primitiva. El material que habíamos reunido se repartió en dos volúmenes diferentes de otra revista alicantina ${ }^{8}$, y yo desistí de fundar una revista científica en la Universidad de Alicante, ya

${ }^{7}$ Ver presentación de estas últimas publicaciones en apartado siguiente.

${ }^{8}$ En la Revista del Instituto de Estudios Alicantinos, de la Diputación de Alicante, volúmenes 36, 1982 (artículos de Epalza, Llobregat y Rubiera) y 37, 1982 (artículos de Molina López, Azuar Ruiz, Poveda i Sánchez y Barceló Torres). 
que confieso mi tendencia a abandonar proyectos altruistas, a la menor dificultad.

Fue Rubiera la que retomó la idea de una revista científica arabista para la Universidad de Alicante, aportando un entusiasmo innovador, una red importante de colaboradores y una ayuda financiera, de sus antiguos proyectos de investigación de la Universidad Complutense. Me dejo que fuera yo el Director (figurando ella de Secretario del Comité de Redacción, en los vols. 1 al 6, y de Co-Director, del 7 al 9), con una generosidad y modestia que le caracterizan: que se hagan las cosas provechosas para la Universidad, ante todo. Fue también y principalmente orientación suya el haber sabido dar a la revista una temática que permitiera publicar en Sharq Al-Ándalus a sectores del arabismo español e internacional que no tenían órgano propio en el panorama de las revistas arabistas españolas de principios de los 80 (la situación ha variado, después, y ha llevado a la revista a hacer los reajustes de "política de publicación científica" adecuados, para una más eficaz planificación). Si la revista tenía una prioritaria orientación inicial hacia la historia árabe de la región oriental de la Península Ibérica (el XarcAl-Ándalus, de los árabes), en todas sus épocas y manifestaciones, con aberturas hacia la historia general de Al-Ándalus y hacia las relaciones hispano-magrebíes modernas, se especializó ya en sola la historia de Xarc-Al-Ándalus (a partir del volumen 8) y en los estudios sobre las minorias musulmanas hispánicas de mudéjares y moriscos (a partir del próximo volumen 12).

Con razón, pues, esta revista Sharq Al-Ándalus. Estudios Árabes dedica este volumen 10-11 (1993-1994) a un Homenaje a Marla Jesús Rubiera Mata, que fue su fundadora y animadora, desde sus inicios, y que ha sabido animar al grupo de investigadores arabistas de la Universidad de Alicante y a la red de sus colaboradores internacionales, durante todos estos años.

No hay que olvidar, además, los trabajos valiosos, personales y en colaboración, que ha publicado en nuestra revista?.

${ }^{9}$ Ver, en el listado de la "Bibliografía de $\mathbf{M}^{\mathbf{a}}$ Jesús Rubiera Mata", al inicio de este volumen, los numerados $34,35,36,44,50,51,61,72,79,93,106$. 
La Colección "Xarc-Al-Ándalus" y otros libros en la Universidad de Alicante.

La profesora Rubiera Mata, además de la revista Sharq Al-Ándalus. Estudios Árabes y de otras publicaciones, españolas y extranjeras (cofundadora de la revista $A w r a ̈ q$, en 1978 -del Instituto Hispano-Árabe de Cultura-, forma parte del Consejo Asesor de Al-Qanțara, desde 1987 -del Consejo Superior de Investigaciones Cientfficas-, las dos importantes revistas de investigación arabística de la capital de España), inició pronto la publicación de libros, en las colecciones de la Universidad de Alicante.

El primero fue un libro colectivo, en que se recogian las conferencias de un ciclo de especialistas reunidos alrededor de un tema filológico candente en la sociedad de la Comunidad Valenciana: el origen de la lengua valenciana y sus relaciones con las lenguas habladas en estas tierras en época árabe, antes de su conquista por Jaime I, en el siglo XIII. El librito Las lenguas prevalencianas ha tenido un cierto éxito, ya que ha sido reeditado por la Universidad ${ }^{10}$.

También publicó, en la Universidad de Alicante, para uso pedagógico de sus alumnos de la asignatura "Literatura hispano-árabe" (3er curso de Filología) y para otros interesados, el útil librito Bibliografla de la literatura hispano-arabe ${ }^{11}$ y el innovador manual Introducció a la literatura hispano-drab ${ }^{12}$.

Buscando financiamiento y en coedición con ayuntamientos, publicó también en la Universidad de Alicante dos libros, ya de investigación: Villena en las calzadas romana y arabe ${ }^{13}$ y la doble edición Els noms arabs de Benidorm i la seva comarca/Los nombres arabes de Benidorm y su comarca ${ }^{14}$.

${ }^{10} 1986$ y 1989 . Los autores del volumen son F. Corriente, A. Galmés de Fuentes; J. A. Frago, J. Solà, A. Ferrando, M. J. Rubiera, J. L. Román del Cerro, M. de Epalza, L. Alpera.

11 1988, 75 páginas.

121989,117 páginas.

${ }^{13}$ Alicante, 1975, $62 \mathrm{pp}$.

${ }^{14}$ Con la colaboración de M. de Epalza e ilustraciones de José María Hidalgo 
Estas experiencias y la de los suplementos bibliográficos de la revista Sharq Al-Ándalus. Estudios Árabes ${ }^{15}$ llevaron a Doña María Jesús a iniciar la aventura editorial de publicar una colección de libros de temas árabes, no necesariamente regionales, pero de interés universitario. Cinco volúmenes de la Colección "Xarc-Al-Ándalus", por ella fundada y dirigida, han salido ya ${ }^{16}$. Las dificultades de edición y financiación no le han arredrado en esta tarea universitaria, siempre dispuesta a encontrar nuevas fórmulas de actividades de fomento de publicaciones.

Hay que mencionar también otras dos publicaciones colectivas en la Universidad de Alicante, organizadas por Doña María Jesús: los textos de la mesa redonda de la Associació Universitària Joan Fuster sobre La problematica actual de l'Islam ${ }^{17}$ y el manual pedagógico para los estudiantes de la Licenciatura de Filologia Árabe Introducción a los estudios arabes e islámicos ${ }^{18}$.

de Cisneros, en 1985, 65 págs. Este libro mereció el primer "Premi de Investigació Ciutat de Benidorm", en 1985, y el "Premi Menéndez y Pelayo" del Institut d'Estudis Catalans, en 1988.

${ }^{15}$ F. Franco Sánchez, Bibliografia sobre temas árabes de las Baleares, 1986, 44 pp., y P. Balañà i Abadía, Els musulmans a Catalunya (713-1153). Una aproximació bibliogràfica, 1986, $47 \mathrm{pp}$.

${ }^{16}$ María Jesús Rubiera i Mata, Introducció a la literatura hispano-àrab, presentació de Rafael Alemany i Ferrer, 1989. Marcelino Villegas, La narrativa de Naguib Mahfuz. Ensayo de síntesis, 1991. Álvaro Galmés de Fuentes, Toponimia de Alicante (La oronimia), 1990. Francisco Franco Sánchez / María Sol Cabello, Muhammad Ašš́s̆afra. El médico y su época, prólogo de María Jesús Rubiera Mata, 1990. Luis F. Bernabé Pons, Bibliografia de la literatura aljamiado-morisca, 1992.

${ }^{17}$ 1993. Los participantes fueron M. J. Rubiera, J. A. Ybarra, M. de Epalza y P. Baldoví.

${ }^{18}$ Autores: M. J. Rubiera Mata (ed.), L. F. Bernabé Pons, H. M. G. ElEryan, M. de Epalza, J. Forcadell, F. Franco Sánchez, E. Lapiedra, J. Zanón, 1994, 123 pp. Mejorada edición en catalán-valenciano Introducció als estudis àrabs $i$ islàmics, Universitat d'Alacant, Alicante, 1994, 131 pp. 


\section{Publicaciones particularmente vinculadas con la Universidad de Alicante y su región.}

Los estudios árabes en España, desde sus inicios científicos a finales del siglo XVIII y a lo largo de su desarrollo investigador y universitario de más de dos siglos, se han caracterizado por ser una forma de "hispanismo" ${ }^{19}$. Se ha dado una natural prioridad al estudio de la presencia árabe-islámica en el territorio actualmente español, siendo de importancia secundaria los estudios sobre el Oriente y el Mágreb medievales y modernos, preponderantes en el resto del arabismo $u$ "orientalismo" europeo. Esta prioridad se justifica, evidentemente, por la larga presencia islámica en la Península Ibérica (más de nueve siglos) y por la permanente vecindad de España con el mundo árabe-islámico. El peso de esa historia común con el Mundo Árabe es evidentemente mayor en España que en otros países europeos con presencia árabe antigua (los Estados de Portugal, Andorra, Francia, Italia, Malta y Grecia -en la Creta medieval, además de la presencia turco-otomana en toda la Península Balcánica e islas adyacentes-). Esta tradición científica y universitaria española explica la prioritaria dedicación de Doña María Jesús al estudio de Al-Ándalus, la "Hispania islamizada", aunque siempre en el marco del mundo árabe en general y de sus relaciones con el mundo hispano, medieval y moderno. Esto explica también su interés por la historia árabe de la región alicantina, cuando vino a ejercer su labor universitaria, docente e investigadora, en la Universidad de Alicante.

${ }^{19}$ Sobre estos estudios árabísticos y su bibliografía, veanse visiones globales de A. Cortabarría, "L'état actuel des études arabes en Espagne", MIDEO, El Cairo, 8 (1966), pp. 75-130 (traducido y ampliado en El arabismo en la España contemporánea (contribución para una historia de los estudios árabes en España), Caldas de Besaya, 1968); J. T. Monroe, Islam and the Arabs in Spanish scholarship, Leiden, 1970; M. Manzanares de Cirre, Arabistas españoles del siglo XIX, Madrid, 1972; M. de Epalza, "Arabic studies in Spain today", Middle East Studies Association Bulletin, New York, vol. 8/2, 1-7 (1974), y "Les études arabes en Espagne: institutions, chercheurs, publications", Annuaire de l'Afrique du Nord, Aix-en-Provence, XV (1976), pp. 1.015-1.029. Los estudios particulares y la bibliografía sobre el arabismo español se han incrementado mucho, estos últimos veinte años, como puede comprobarse en los trabajos de este mismo volumen. 
Hay también una larga tradición de universitarios arabistas españoles modernos que, al desplazarse de Madrid (Doña María Jesús es madrileña de varias generaciones por línea femenina, y de padre asturiano) a Universidades de otras regiones españolas, se han interesado por su historia árabe y han hecho importantes aportaciones a esa historia "hispana" regional ${ }^{20}$. La profesora Rubiera Mata lo ha hecho con profesionalidad y dedicación, desde los primeros años de su actividad universitaria en Alicante, como ya pudo verse en la fundación de la revista Sharq Al-Ándalus. Estudios Arabes y su red de colaboradores. Otras colaboraciones en este volumen-homenaje abordan algunos aspectos de su entusiasta dedicación a la investigación sobre ese "XarcAl-Ándalus" ("Oriente de la Península lbérica árabe"), a muchos niveles.

Sin poder abarcar los detalles de esa actuación, hay que destacar que muchas de sus actuaciones en la región se debieron a peticiones de autoridades o personalidades locales, y hasta de algunos alumnos (de Aspe, de Benissa, de Benidorm, de Denia, de Elda, de Crevillente, de Murcia, de Onda, de Petrer, de Valencia, de Xàtiva, de Villena...), tanto en el campo de las publicaciones y actividades científicas (libros -alguno reeditado, como La Taifa de Denia-, artículos, congresos...), como de divulgación o extensión universitaria (conferencias, folletos de fiestas, pregones...). En los dos extremos, quizás, de la gama de su entusiasta actividad pasada, en respuesta a demandas locales, se pueden mencionar su organización de un Simposio Científico Internacional sobre la alimentación árabe, en Xàtiva ${ }^{21}$, y el pregón de la Fiesta de Moros y Cristianos, en Benissa, pronunciado en valenciano, en 1988.

${ }^{20}$ Véanse, como ejemplo, los libros de P. Martỉnez Montávez, Perfil del Cádiz hispano-árabe, Cádiz, 1974, y M. J. Viguera Molíns, Aragón musulmán, Zaragoza, 1971, por mencionar dos casos de colaboradores de este volumenhomenaje.

${ }^{21}$ Simposio "Alimentació i Societat en la Cultura Islámica", en 1991, con la Dra. Manuela Marín, del Consejo Superior de Investigaciones Científicas de Madrid, colaboradora de este volumen-homenaje. Las Actas de ese Simposio se han publicado en el libro La alimentación en las culturas islámicas (M. Marín y D. Waines, eds.), Madrid, 1994, con el trabajo de M. J. Rubiera Mata, "La dieta de Ibn Quzmān. Notas sobre la alimentación andalusí a través de su literatura", pp. 127-136. 
A niveles políticos, se adhirió a un partido político que canalizara en la práctica sus ideales y su actividad de mejora social, el CDS, y hasta fue invitada a presentar una ponencia sobre los temas culturales y linguísticos regionales, en la convención de Benicàssim de 1987.

Esta actividad posibilista de mejora social le ha llevado a actividades en defensa de la igualdad de derechos y oportunidades de personas de sexos, razas, lenguas, culturas y orígenes diferentes. Su actual actividad, discreta pero eficaz, en favor de las mujeres universitarias argelinas exiliadas de su país, es un buen ejemplo de ese amplio interés de Doña María Jesús en este campo, actividad suya local e internacional al mismo tiempo.

Sobre su interés y apoyo en favor de la lengua y de la cultura regionales en lengua catalana, con particular cuidado por respetar sus variantes valencianas, se habla en otro trabajo de este volumenhomenaje $e^{22}$ y en apartado específico, al final de este artículo. Doña Maria Jesús Rubiera i Mata (como firma sus escritos en esa lengua) ha hecho investigaciones sobre relaciones entre literatura árabe y literatura catalana, medieval (jarchas, Tirant Lo Blanch, Turmeda...) y moderna (Joan Fuster...) y sobre léxico y toponimia valencianas, redactando alguno de sus libros y numerosos artículos en lengua catalana, estos últimos años ${ }^{23}$. Ha presentado los resultados de estas investigaciones de catalanística tanto en congresos cientificos (Aix-en-Provence, Alicante, Barcelona, Elx/Elche, Nápoles, Reus, Strasbourg, Toulouse...), como en conferencias universitarias (Madrid, Murcia, Valencia...) y extra-universitarias (Alfas del Pi, Altea, Denia, Gandía...). Ella organizó, con otros miembros del entonces Departamento de "Filologías Árabe, Catalana y Francesa", un seminario de expertos, para la "normalización" o normativización de diversos sistemas de transcripción de los arabismos en catalán ${ }^{24}$. Ella ha sido también uno

${ }^{22}$ Ver artículo del Dr. Rafael Alemany i Ferrer, que le había hecho el prólogo de su libro Introducció a la literatura hispano-àrab, Alacant, 1989, pp. 9-13.

${ }^{23}$ Ver su bibliografia, en este volumen-homenaje.

${ }^{24}$ Ver aportación de este seminario de la Universidad de Alicante de 1986, expresamente reconocido como origen de la normativa del Institut d'Estudis Catalans, en "Proposició sobre els sistemes de transliteració i transcripció dels 
de los miembros fundadores del colectivo universitario de la Universidad de Alicante "Associació Universitària Joan Fuster", en 1993. Esta actividad de difusión y apoyo de la cultura en una de las dos lenguas de nuestra Comunidad es muy propia de una intelectual de Letras, abierta a las riquezas culturales de cualquier origen, pero ha supuesto para ella un gran esfuerzo, admirable, al no ser de lengua catalana, lengua cuyo uso, oral y escrito (no el leído, que conocía, como persona culta), aprendio en la Universidad de Alicante.

El origen de su interés por fomentar esa lengua de la Comunidad Valenciana (llamada oficialmente "valenciano" y cientificamente "lengua catalana", con sus variantes regionales) puede encontrarse en tres grupos de razones: por ser lengua oficial de la Comunidad y por tanto de sus funcionarios, que han de "normalizarla" en su uso, junto al omnipresente castellano o español; por ser una lengua de gran interés cultural y cientifico, también para un arabista, que encuentra múltiples temas de investigación a caballo entre las dos lenguas y las dos culturas; por haberse encontrado en un Departamento y con unos colegas universitarios que hablaban esa lengua y la estudiaban, a diversos niveles del quehacer universitario.

Nuestra Universidad ha sido también testigo local de su actividad por temas de interés regional, sea a iniciativa de ella (el mencionado simposio sobre "Las Lenguas pre-valencianas") o a petición de colegas universitarios de la Universidad de Alicante, el año pasado ${ }^{25}$.

mots àrabs al català", Documents de la Secció Filològica, I, Barcelona, 1990, 140-158. Ver también L. Martín i Pascual, "Reunió técnica per la normalització de noms i textes d'origen àrab", Sharq Al-Andalus..., 4 (1987), pp. 377-383; L. B. Polanco Roig, "Sistemes de representación gràfica de mots àrabs en català", Sharq Al-Ándalus..., 5 (1988), pp. 11-30.

${ }^{25}$ Como su participación en el Coloquio Internacional "Literatura y Espacio Urbano" (marzo-abril 1993), organizado por el prof. José Carlos Rovira (volumen publicado con ese mismo título, en 1994, con el capítulo de María Jesús Rubiera "La ciudad como jardín y el jardín como ciudad: la Alhambra", pp. 175-185), o en la mencionada mesa redonda "La problemática actual del Islam", organizada por Josep Forcadell, Colaborador Honorífico de nuestro Departamento (capítulo de María Jesús Rubiera, "L'Islam: àrabs i musulmans", publicado en 1993, pp. 7-22), ambos participantes con sendos trabajos en este volumen-homenaje. 
La variedad de actividades y de temas de interés que ha desarrollado María Jesús Rubiera en la región de Alicante, a partir de su puesto universitario, muestra su capacidad de relacionarse con la gente, de hacerse amigos -a veces mudables, como la vida misma-, de interesarse por los demás, por sus curiosidades, de ponerse al servicio de una revista, de un concejal, de un colega, de un estudiante, investigando las muchísimas huellas árabes en tierras alicantinas y xarquies en general. Sus estudios sobre la toponimia árabe de la región no han sido localistas, sino con amplias perspectivas filologicas y de estructuración de los espacios humanos; pero para ello, y en la tradición del profesor Elías Terés y del mejor arabismo español, se ha "pateado" el terreno, visitando los lugares concretos donde se daban esos topónimos de origen o época árabes. Ha amado a esta tierra en su época musulmana árabe, defendiendo su riqueza árabe, negada por investigadores que querían "transformar la gran civilización urbana de Al-Ándalus en un inculto aduar beréber", única "batalla" ideológica que, por razones científicas, emprendió en el terreno arabístico. Dos preciosos estudios sobre la ciudad y las tierras valencianas son un resumen maravilloso de lo que supo leer sobre ellas en los textos literarios árabes ${ }^{26}$.

\section{Investigación, dirección de investigación y fomento de investigación}

Es papel muy importante de la labor universitaria el realizar una investigación cient́fica, a nivel personal y colectivo. La investigación no es todo, en la labor universitaria, pero indica su más alto nivel. Doña María Jesús, que venía a la Universidad de Alicante desde el Departamento de Árabe de la Universidad Complutense de Madrid, con secular tradición de afamada investigación en los estudios árabes e islámicos, inició con todo entusiasmo su labor investigadora en Alicante, con fe en las posibilidades de hacer una investigación de calidad en una Universidad nueva (la Universidad de Alicante tiene

26 "La cultura musulmana: pensament, lenguatge i formes literàries (Aspectes de la poesia aràbigo-valenciana: el paradís i el paradís perdut)", En torno al 750 Aniversario. Antecedentes y consecuencias de la conquista de Valencia, Valencia, 1989, pp. 98-106, y "Arquetipos ideales de la ciudad islámica", La Ciudad Islámica, Zaragoza, 1991, pp. 289-295. 
raíces en el Centro de Estudios Universitarios -C.E.U.- dependiente de la Universidad de Valencia, desde 1968, pero no se convirtió en Universidad hasta 1981, un año antes de la llegada de la Dra. Rubiera). Según Doña María Jesús, se trataba de adaptarse a las posibilidades de esta nueva situación, tanto en el campo de su investigación personal como en el de integrar equipos y de formar investigadores. Aquí puede tener cierta satisfacción: el haber conseguido crear un pequeño grupo compacto -estructurado- de investigadores, en diversas líneas de investigación.

A nivel personal, cuando se mira los títulos de la bibliografía de Rubiera Mata, con sus publicaciones, que son parte del resultado de su investigación, se puede ver cómo prosiguió personalmente en la Universidad de Alicante sus investigaciones en diversos temas que llevaba tratando en años anteriores, especialmente lo relacionado con la historia del reino nazarí de Granada (siglos XIII-XV), con el arte epigráfico de los palacios de la Alhambra, con la literatura árabe de AlÁndalus y con el arte y la arquitectura en la literatura árabe. Pero inició también, con formación previa importante que no había aplicado a esos temąs, unas nuevas líneas de investigación condicionadas por su nueva situación en la Universidad de Alicante. Son, sobre todo, sus estudios sobre Xarq-Al-Ándalus (historia regional y local, toponimia de origen árabe, los espacios viales de los itinerarios que estructuran la región, algunos personajes históricos y literarios árabes originarios de Denia, Valencia, Xàtiva, Alzira, Orihuela, Calpe, Benissa, etc.) y sobre las relaciones entre lengua y literatura árabes y cultura catalana (influencias árabes en la onomástica y el léxico catalanes, sobre la poesía de las jarchas, sobre la narrativa de Tirant Lo Blanch, sobre relatos de Turmeda, etc.). Sus logros se han publicado ya en parte y son objeto de comentarios en otras páginas de este volumen. La breve enumeración precedente, de temas que cambian la visión tradicional de la historia regional en época árabe, merecen una lectura detenida de los títulos de su bibliografia que se refieren a cada uno de esos temas.

A nivel colectivo, de formación de jovenes investigadores y de equipos de investigación, su trabajo ha sido también importante, aunque los resultados no han sido siempre tan positivos, por la lentitud de los resultados y por depender también no sólo de ella, sino de elementos 
humanos del personal disponible para esta labor investigadora de dirección personal y en equipo.

En lo que se refiere a formación de jóvenes investigadores, emprendió con entusiasmo la labor de iniciar en la investigación a los pocos licenciados de árabe que se encontraban en la región de Alicante. Les ayudó a hacer la "tesina", Memoria de Licenciatura o Trabajo de Investigación, les dio también temas para iniciarse en la publicación de los mejores resultados de sus investigaciones y les preparó para participar en congresos científicos, nacionales e internacionales. También solventó, en el ámbito de los estudios árabes de la Universidad de Alicante, las dificultades administrativas para hacer las tesinas aquí, aunque no hubiera la licenciatura de árabe. Sólo tres tesinas, en temas especificos de su especialidad (la difícil materia de la literatura árabe, medieval y moderna) llegaron a realizarse, con su esforzada ayuda ${ }^{27}$. Ninguno de estos jóvenes arabistas, provenientes de la Universidad de Granada pero "graduados" con su Memoria en la de Alicante, han proseguido -por ahora...- su carrera de investigador, que Doña María Jesús había fomentado con pequeñas publicaciones primerizas, además de la tesina ${ }^{28}$. También colaboró, con gran generosidad, en los trabajos de formación y de tesinas que dirigfan otros colegas arabistas de la Universidad (Dres. Villegas y Epalza) ${ }^{29}$. Promovió a buenos estudiantes de Alicante para que prosiguieran el Segundo Ciclo de Árabe en otras Universidades, aunque vinieran luego a la Universidad de Alicante

${ }^{27}$ Hay que mencionar las de Marisol Cabello García, Amirat al-Andalus de Ahmad Šawgi (29-10-1986), y de Teófilo Gallega Ortega, Poetas árabes de Játiva. Siglos XII-XIII (12-06-1990).

28 Ver María Sol Cabello García, "Amirat Al-Andalus de Ahmad Šawqi", Sharq Al-Ándalus..., 4 (1987), pp. 31-34, y M. J. Rubiera Mata, "Prólogo" a F. Franco Sánchez - M. S. Cabello, Muhammad aššs̆afra. El médico y su época, Alicante-Crevillente, 1990, pp. 13-15.

29 Una sola tesina de arabista, de Sol Martínez Martínez-Tercero, Los arabismos de Gabriel Miró (22-11-1985), pero también tesinas de Luis Fernando Bernabé Pons, El manuscrito del morisco hispano-tunecino Ybrahim Taybili (Juan Pérez) (12-01-1987), y de Francisco Franco Sánchez, Estudio de los espacios urbanos de la ciudad de Orihuela en el periodo islámico (11-05-1987). Los tres trabajos fueron publicados ulteriormente, en Alicante, Zaragoza y Alicante, respectivamente. 
a realizar el Tercer Ciclo y el Doctorado en Filología Árabe ${ }^{30}$. En la nueva etapa de la Licenciatura y Doctorado de Filología Árabe en la Universidad de Alicante (desde 1993 y 1991, respectivamente), es posible y muy probable que puedan formarse localmente nuevas hornadas de investigadores jóvenes, arabistas de la región y de otras regiones. La ingratitud de algunos de esos arabistas, que promovieron contra la profesora Rubiera una feroz e inmotivada campaña, ha motivado, en parte, este homenaje, para demostrar a nuestra colega que ese caso desgraciado es excepcional.

Marfa Jesús Rubiera, a la vista del limitado número de arabistas a los que iniciar en la investigación, en Alicante, emprendió también la compleja tarea de formar investigadores de otras áreas científicas, en temas "puente" entre los estudios árabes y los estudios hispánicos de variada Indole, a veces en co-dirección con profesores de esas otras áreas: de historia ${ }^{31}$, de filologia española ${ }^{32}$, de filología catalana ${ }^{33}$ y de filología inglesa ${ }^{34}$. Su inmensa cultura y su capacidad de colabo-

${ }^{30}$ El caso de Eva Lapiedra Gutiérrez, que leyó su tesina en la Universidad de.Alicante, el 07-04-1992: Textos y denominaciones referidas a cristianos en las crónicas árabes (siglos VIII-X).

31 Eneida García Garijo, resumida en "La Alcoraya: un espacio histórico, agrícola y vial", Sharq Al-Andalus..., 4 (1987), pp. 153-158, y "La alcoraya alicantina y las alcorayas baleáricas", Les Illes Orientals..., pp. 165-172. Ha publicado también otros trabajos sobre relaciones de la cultura árabe y la música europea, como "La influencia de la música árabe en la española desde mediados del siglo XIX hasta los años 30", Sharq Al-Ándalus..., 5 (1988), pp. 69-88. Esta dirección fue particularmente importante en la tesis de Francisco Franco Sánchez, mencionada infra, dirigida oficialmente por el Prof. Eloy Benito Ruano y presentada en la UNED.

${ }^{32}$ Tesina de Pino Valero Cuadra, "La doncella Teodor": un cuento hispanoarabe, (16-10-1990), y la tesina de Luis Fernando Bernabé, mencionada en la nota 29.

${ }^{33}$ Llúcia Martín Pascual, El deute de la "Història de Jacob Xalabin" amb la tradició oriental. Extensió $i$ límits, resumida en "Les fonts orientals de la Història de Jacob Xalabin", Sharq Al-Ándalus..., 5 (1988), pp. 101-109.

${ }^{34}$ Tesina de Ovidio Carbonell Cortés La España mora en la literatura romántica inglesa (06-12-1989), en parte publicada en "Ecos de historia romántica: la «España mora» en Thomas Rodd y Washington Irving", Sharq AlÁndalus..., 8 (1991), pp. 11-24. 
ración desinteresada, con tal de obtener resultados universitarios positivos, le permitieron realizar este complejo trabajo de formación de jóvenes, lleno de satisfacciones, pero también de desilusiones. Así asumen los formadores universitarios el que no siempre se realicen las esperanzas puestas en muchas promesas, con la satisfacción de ver al menos algunos resultados.

Para esta tarea de formación de investigadores -una meta fundamental de la Universidad, que la distingue de otras instituciones docentes, públicas y privadas-, se preocupo en primer lugar por las infraestructuras docentes y administrativas. Ya se ha mencionado cómo consiguió que los licenciados de árabe pudieran leer su Memoria de Licenciatura en Alicante. Para el Tercer Ciclo y el Doctorado, no era posible hacer una especialidad de árabe (Filología Semítica), por no tener nuestra Universidad más que el Primer Ciclo y no la Licenciatura entera. Por eso, se asoció con otras ramas de Filología, para impartir cursos de Tercer Ciclo, que fueran convalidables en otras Universidades, para obtener allí el Doctorado: con Filologia Inglesa, luego con Filología Catalana y con Filología Francesa. Finalmente, una disposición oficial que permitía el caso excepcional de impartir el Tercer Ciclo y el Doctorado de una especialidad que no tuviera la Licenciatura o Segundo Ciclo, si se tenía personal e infraestructuras de nivel científico suficiente para esta docencia y dirección investigadoras, permitió que el Consejo de Universidades concediera a la Universidad de Alicante, en 1990, el Tercer Ciclo y el Doctorado de "Filología Árabe". Todas las iniciativas, gestiones y trámites para obtener esta infraestructura académica y administrativa en la Universidad de Alicante corrieron a cargo de la Dra. Rubiera Mata.

En cuanto a la infraestructura interna, trajo su Proyecto de Investigación de la Universidad Complutense, al trasladarse a la Universidad de Alicante. Con parte de esos fondos se financió el primer número de la revista de investigación arabística Sharq Al-Ándalus. Estudios Arabes, imposible de financiar en Alicante, como se ha expuesto anteriormente. Esta revista ha sido, estos últimos años, no sólo expresión de la investigación arabística del equipo de la Universidad de Alicante, sino también una infraestructura colectiva para animar muchos investigadores de la región, de toda España y de otros países, a que 
investigaran sobre el pasado árabe de la región y sobre otros temas del ámbito árabe e islámico.

Ya en la Universidad de Alicante, obtuvo en 1988 para nuestro grupo de investigación la financiación del Proyecto -de la DGICYT del Ministerio de Educación y Ciencia- "Corpus historiográfico y criticoliterario de la literatura hispano-arabe", que agrupó a todos los investigadores y a algunos estudiantes. De este proyecto iban a salir, sobre todo, dos libros suyos de conjunto sobre esta literatura ${ }^{35}$, importantes por no haberse escrito una síntesis así, en España, desde hacía más de medio siglo ${ }^{36}$. Dos libros bibliográficos iban a ser también fruto de este proyecto ${ }^{37}$.

Más adelante la Profesora Rubiera Mata obtuvo de la Generalitat Valenciana el financiamiento de dos proyectos E.V.A. de investigación sobre arabismos en catalán, que darian lugar a otro libro colectivo ${ }^{38}$.

Doña María Jesús no sólo ha fomentado proyectos colectivos de investigación que ella dirigía, sino que ha sabido colaborar en proyectos colectivos dirigidos por otros, desde la Universidad de Alicante. Ella ideó el programa conjunto hispano-norteamericano "El espacio como expresión de la sociedad del Sharq Al-Ándalus (Levante de la Pentnsula Ibérica) en época musulmana y mudéjar", co-dirigido por Míkel de Epalza y el medievalista Robert Ignatius Burns, de la Universidad de California-Los Ángeles ${ }^{39}$. Y participó, en diversa medida, en las actividades del grupo regional de investigación "Urbanismo musulmán"40. Por sus iniciativas en la organización de la investigación

35 Introducció a la literatura hispano-àrab, Alicante, 1989, y Literatura hispano-árabe, Madrid, 1992.

36 Ver A. González Palencia, Historia de la literatura arábigo-española, Madrid, 1926; $2^{\text {a }}$ edición, Madrid, 1945, ampliada, pero con metodología muy diferente.

${ }^{37}$ María Jesús Rubiera Mata, Bibliografia de la literatura hispano-árabe, Alicante, 1988, y Luis Fernando Bernabé Pons, Bibliografia de la literatura aljamiado-morisca, Alicante, 1992.

${ }^{38}$ Vocabulari aràbigo-islàmic, en prensa.

${ }^{39}$ Principales resultados, publicados o recensionados en la revista Sharq AlAndalus. Estudios Arabes.

${ }^{40}$ Ver presentación global en M. de Epalza, "Études d'éléments urbanistiques 
colectiva que desembocó en el congreso sobre "Ibn al-Abbär de Valencia y su tiempo", en 1989, se le pidió diera la conferencia

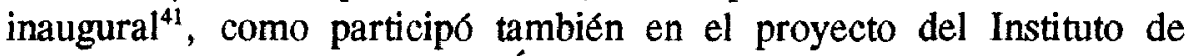
Cooperación con el Mundo Árabe sobre el "Madrid árabe", cuyos resultados no han sido todos publicados ${ }^{42}$.

Sobre su aliento a toda iniciativa de investigación pueden atestiguar muchos colegas, especialmente los doctorandos y doctorados de la Universidad de Alicante $^{43}$, y hasta algún estudiante, al que ayudó a ganar un premio, contra sus propios intereses ${ }^{44}$. Yo mismo tengo que

d'Al-Andalus", Les Cahiers de Tunisie, XXXIV/137-138 (1986), pp. 131-138. Principales publicaciones colectivas: Agua y poblamiento musulmán, Benissa, 1988; Baños árabes en el País Valenciano, Valencia, 1989; La Ciudad Islámica, Zaragoza, 1991. En este grupo, su intuición sobre la localización probable de la mezquita de la placa de Guardamar, cerca de una fuente de agua, fue decisiva para las pesquisas que desembocaron, en 1984, en el descubrimiento por Rafael Azuar de las 22 mezquitas o rábitas de Al-Munastir de Xarq-Al-Ändalus, en las dunas de Guardamar del Segura (ver M. de Epalza (coord.), La Ràita Islàmica: Història Institucional..., Sant Carles de la Ràpita, 1993, 1994, y "La espiritualidad militarista del Islam medieval. El ribat, los ribates, las rábitas y los almonastires de Al-Ándalus", Medievalismo, Madrid, 3 (1993), pp. 5-18).

${ }^{41}$ Ver volimen M. de Epalza - J. Huguet (coords.), Ibn Al-Abbar. Polític $i$ escriptor àrab valencià (1199-1260), Valencia, 1990, pp. 13-18.

${ }^{42}$ Ver "La toponimia árabe de Madrid", Madrid del siglo IX al XI, Madrid, 1990 , pp. 165-170, y prólogo a la reedición de J. Oliver Asín, Historia del nombre "Madrid", Madrid, 1991, pp. I-XVI, mientras que su preciosa conferencia inaugural "Maŷriț/Magerit/Madrid. Carácter de una ciudad en su contexto árabe-islámico", del Congreso Internacional La fundación de Madrid y el agua en el urbanismo islámico y mediterráneo, Madrid, 22-26 de octubre de 1990, no llegó a publicarse, por no publicarse las Actas del Congreso.

${ }^{43}$ Los Dres. Luis Fernando Bernabé Pons (con una tesis sobre Edición y Estudio del Manuscrito Español del Evangelio de Bernabé, evangelio hispano islámico de autor morisco [siglos XVI-XVII]) y Francisco Franco Sánchez (con una tesis sobre Los espacios viales y los espacios defensivos de la Mancha oriental en el periodo islámico), así como Eva Lapiedra Gutiérrez y Pino Valero Cuadra, que tienen sus tesis muy avanzadas.

44 Ver al menos tímido agradecimiento en prólogo y bibliografía de Vicent Martines, Temps de croada, temps creuats. El Xarq Al-Andalus, un espai d'òsmosi, Onda, 1991, pp. 4, 126-127. 
confesar su generosidad cientifica en hacerme participar en sus investigaciones y publicaciones ${ }^{45}$.

No se puede dejar de mencionar dos características más de la actividad de Doña María Jesús en su capacidad de organización de la investigación: el carácter interdisciplinar que sabe dar a sus trabajos y al de sus colaboradores y el carácter internacional de muchas de sus actividades (proyectos ERASMUS para intercambio con profesores y alumnos; intercambios con Argel, Orán, Nápoles, Roma, Venecia, Turín, Montpellier, Toulouse, Bruselas, Bielefeld, Los Ángeles, Lisboa...). Ha sido una proyección internacional selectiva, en función de proyectos y realizaciones concretas, realistas y eficaces.

\section{Actividad en la organización académica del Departamento}

María Jesús Rubiera Mata, al llegar a la Universidad de Alicante, asumió las modestas y relativamente sencillas funciones de Jefe de la División de Estudios Árabes e Islámicos, puesto que le correspondía por ser el profesor numerario con más antigüedad. Pero, a los pocos meses, tuvo que participar en la reorganización de la Facultad de Filosofia y Letras de la Universidad de Alicante, para ajustarse al diseño de Departamentos como unidad administrativa de personal, de docencia y de investigación, que había establecido la L.R.U. (Ley de Reforma Universitaria). Esta reorganización afectaba de una manera particular a aquellas "Áreas de conocimiento" cuyo número de profesores no alcanzaba los mínimos exigidos por la ley (9 en etapa provisional, 12 al terminarse el plazo provisional). Casi todas las áreas de conocimiento de nuestra Facultad no alcanzaban ese número y tuvieron que formar Departamentos entre varias áreas afines, con negociaciones a veces

${ }^{45}$ En especial el novedoso estudio "La sofra (sujra) en el Sharq Al-Ändalus antes de la conquista catalano-aragonesa",Sharq Al-Ándalus..., 3 (1986), pp. 3337 (cuyo texto fue traducido al francés -mencionando evidentemente la fuente-por P. Guichard, L'Espagne et la Sicile musulmanes awx XIe et XIle siècles, Lyon, 1990, pp. 179-180); "Los cristianos toledanos bajo dominación musulmana", Simposio Toledo Hispano-Árabe, Toledo, 1986, pp. 129-133; Los nombres árabes de Benidorm y su comarca, Alicante, 1985; Xàtiva musulmana (segles VIII-XIII), Xàtiva, 1987. 
complejas. La Dra. Rubiera llevó a cabo esas tractaciones, que terminaron con la formación de un Departamento de tres áreas afines (Estudios Árabes e Islámicos, Filología Catalana y Filología Francesa). Le tocó de nuevo a la Dra. Rubiera ser Directora provisional, por antiguiedad como numerario, y luego por elección.

Fueron, por tanto, cinco años de duro trabajo, para unificar a las tres áreas, primero en un mismo piso del edificio de Filología, luego en un mismo reglamento que mantuviera la autonomía de las áreas y la colaboración común (elaborado conjuntamente con el Dr. Rafael Alemany) y finalmente en un ambiente de colaboración científica y de compañeros, a múltiples niveles. María Jesús Rubiera Mata, con fe en la institución universitaria y con inteligente imaginación, dedicó también parte de su actividad universitaria de esos cinco años a representar al Departamento y a sus intereses en todas las instancias de la Universidad de Alicante y a niveles locales, nacionales e internacionales, con la dificultad de iniciar un nuevo modelo departamental de Universidad. Hasta tuvo que superar, a veces, la rechifla de algunos, por la heterogeneidad aparente de las áreas de árabe, catalán y francés (aun en la prensa, a la que hubo que explicar públicamente su error, mostrando las afinidades científicas de estas áreas filológicas, expresión de importantes civilizaciones y culturas). Pero hubo gente, de dentro y de fuera del Departamento, que supieron apreciar ese esfuerzo, impuesto por la L.R.U., de un proyecto común, como la escritora catalana Maria Aurèlia Capmany, que dedicó unas líneas de inteligente reflexión al título de nuestro Departamento, que le encantaba: "Nomès que el titol d'aquest departament t'invita a la meditacio sobre les relacions entre cultures i llenglles...A part de l'encant de la Universitat alacantina no em puc estar de fantasiejar sobre el tema d'un departament que inclou àrab, català i francès, una KOINÉ mediterrània"46.

El Departamento que ella fundo, en 1985, sigue adelante: los profesores de Filología Catalana lograron el número suficiente para formar un Departamento propio, de área homogénea. Las otras dos áreas han ido creciendo, pero no podrán alcanzar fácilmente esa meta, por lo que se han adaptado a esa situación de pluralismo y van a

${ }^{46}$ Diario Avui, Barcelona, 7 de mayo de 1989. 
dinamizar esa experiencia universitaria. Se están preparando a ser un Departamento de "Filologías integradas", en las que vayan encontrando su sitio adecuado nuevas áreas de conocimiento de Filología (próximamente alemana y eslava, más adelante italiana, hebrea...), a las que esperamos ofrecer la experiencia de una buena convivencia universitaria y de un apoyo mutuo entre áreas diversas de pocos profesores, dentro del respeto a la tradición científica de cada Filología. Como lo iniciamos, hace casi diez años, bajo la administración de la fundadora del Departamento, la Dra. María Jesús Rubiera Mata.

\section{Proyección internacional y nacional}

No es fácil de evaluar la proyección nacional e internacional de una personalidad cultural o de un profesor de Universidad. Se trata, además, de una proyección variada, con el condicionante añadido de que está en plena actividad, con previsible ampliación de su magisterio universitario, por su actividad directa, por sus publicaciones y por sus ideas. Por todo ello, podría obviarse este apartado, sobre la actividad de Doña María Jesús, en la Universidad de Alicante.

Pero es verdad que ese prestigio no es sólo personal, objeto de modestia, para la catedrático de Estudios Árabes e Islámicos. Forma parte del prestigio de Universidad de Alicante y de su equipo de profesores, especialmente de sus compañeros arabistas. Por eso se mencionarán a continuación algunos hechos -sólo algunos- que muestran ese reconocimiento internacional y nacional.

Se puede mencionar, entre los que a ella más le satisfacieron, el haber representado al Departamento de la Universidad de Alicante en la solemne clausura del Programa "Al-Ándalus-92", en noviembre de 1992, en las majestuosas ruinas de Medina Azahara, el palacio de los califas de Córdoba, con los Reyes de España y un selecto plantel de universitarios árabes y españoles. Podría hablarse del homenaje que le hicieron las Universidades de El Cairo, por sus investigaciones sobre Granada y sobre la Literatura andalusf. $O$ las actividades internacionales a la que es invitada, cursos y conferencias, siempre a título personal, por aprecio y estima a su personalidad intelectual. O muchas otras manifestaciones de su prestigio científico y literario, en el ámbito universitario, cultural y especialmente literario. O la traducción de 
trabajos suyos a otras lenguas (italiano, portugués, francés, alemán...). Todo ello, en favor de la irradiación de nuestros estudios en la Universidad de Alicante.

$$
\text { * * * * }
$$

Con este volumen de Homenaje a Doña María Jesús Rubiera Mata, un buen grupo de colegas y amigos universitarios querrfamos, no sólo reconocer sus notables méritos pasados y especialmente su acción universitaria en Alicante, sino ofrecerle también nuevos ánimos en su futura actividad universitaria, también desde la Universidad de Alicante. 